\title{
Roll-to-Roll Slot-Die Coated P-I-N Perovskite Solar Cells Using Acetonitrile Based Single Step Perovskite Solvent System ${ }^{\dagger}$
}

\author{
Daniel Burkitt ${ }^{a}$, Rahul Patidar $^{a}$, Peter Greenwood $^{a}$, Katherine Hooper $^{a}$, James McGettrick $^{a}$, \\ Stoichko Dimitrov ${ }^{a}$, Matteo Colombo ${ }^{a}, V_{\text {Vasil Stoichkov }}{ }$, David Richards $^{a}$, David Beynon $^{a}$, \\ Matthew Davies ${ }^{a}$, Trystan Watson ${ }^{a}$
}

Received Date

Accepted Date

DOI: $00.0000 / x x x x x x x x x x$
Roll-to-roll coating of all active layers is demonstrated for a P-I-N perovskite solar cell stack, using a single step perovskite ink with an acetonitrile solvent system and flexible plastic substrate. A slot-die coating roll-to-roll process (with a common coating speed for all layers) is developed by using appropriate length meniscus guides as part of the coating head for each ink rheology. High performance devices are demonstrated with four roll-to-roll slot-die coated layers and evaporated top electrode. The drying conditions of the perovskite layer are optimized and found to be critical to achieving good performance. Multi solvent blend systems for the electron collection layer are developed that are more industrially compatible than the commonly used chlorobenzene solvent system and make use of a gradient of solvent volatilities to give both good macro film formation and rapid drying. A stabilised power conversion efficiency of $12.2 \%$ is demonstrated, that is the highest reported to date for devices with all layers other than the top electrode deposited roll-to-roll. This work demonstrates the feasibility of a roll-to-roll fabrication process for perovskite solar cells that could be transferred to a fully inline roll-to-roll process with all coating and drying stages made sequentially on one line running at a common coating speed and further demonstrates the potential to produce high efficiency photovoltaics using roll-to-roll fabrication methods.

\section{Introduction}

Roll-to-roll (R2R) manufacturing of flexible electronics 1 -4 gives the possibility of extremely high throughput production, lowering of fabrication costs 5 , the ability to create continuous large area devices ${ }^{6}$ and to facilitate rapid deployment and decommissioning 7/8. Metal halide perovskite materials have become a large research topic for use in electronic devices due to their exceptional opto-electronic properties. The formation of thin flexible layers of these materials coupled with the ability to solution process and deposit using common printing and coating techniques makes them ideal candidates for roll-to-roll manufacturing. Photovoltaics is one area where the combination of the excellent opto-electronic properties of perovskite materials and roll-to-roll manufacturing could lead to dramatic changes in both cost and

\footnotetext{
a SPECIFIC, College of Engineering, Swansea University, Bay Campus, SA1 8EN Swansea, UK. E-mail: t.m.watson@swansea.ac.uk

$\dagger$ Electronic Supplementary Information (ESI) available: [details of any supplementary information available should be included here]. See DOI: 10.1039/cXCP00000x/
}

production rate, as well as giving access to a range of novel deployment strategies not possible using conventional photovoltaic materials and production methods ${ }^{9}$. Along with this, perovskites are formed of low cost precursor materials that could lower the bill of materials for photovoltaic devices, providing adequate performance and lifetimes can be achieved $10[11$.

Metal halide perovskite materials with the structure $\mathrm{ABX}_{3}(\mathrm{~A}=$ $\left.\mathrm{CH}_{3} \mathrm{NH}_{3}{ }^{+},\left[\mathrm{CH}\left(\mathrm{NH}_{2}\right)_{2}\right]^{+}, \mathrm{Cs}^{+} ; \mathrm{B}=\mathrm{Pb}, \mathrm{Sn} ; \mathrm{X}=\mathrm{Cl}, \mathrm{Br}, \mathrm{I}\right)^{12}$ display many exciting properties that make them good candidates for photovoltaic absorber materials 13 . The ability to easily tune the chemical composition of the material and so the bandgap gives the potential to use in high performance single junction and tandem solar cell applications. Many metal halide perovskite compositions display long charge diffusion lengths ${ }^{14 \mid 15}$ and so high charge extraction efficiencies, low non-radiative recombination losses $\frac{16}{16}$ and high performance. One such composition and one of the most commonly used photovoltaic perovskite absorber materials is $\mathrm{CH}_{3} \mathrm{NH}_{3} \mathrm{PbI}_{3}$, which has been successfully demonstrated in small area devices 17 and in some larger area devices and modules 18 . 


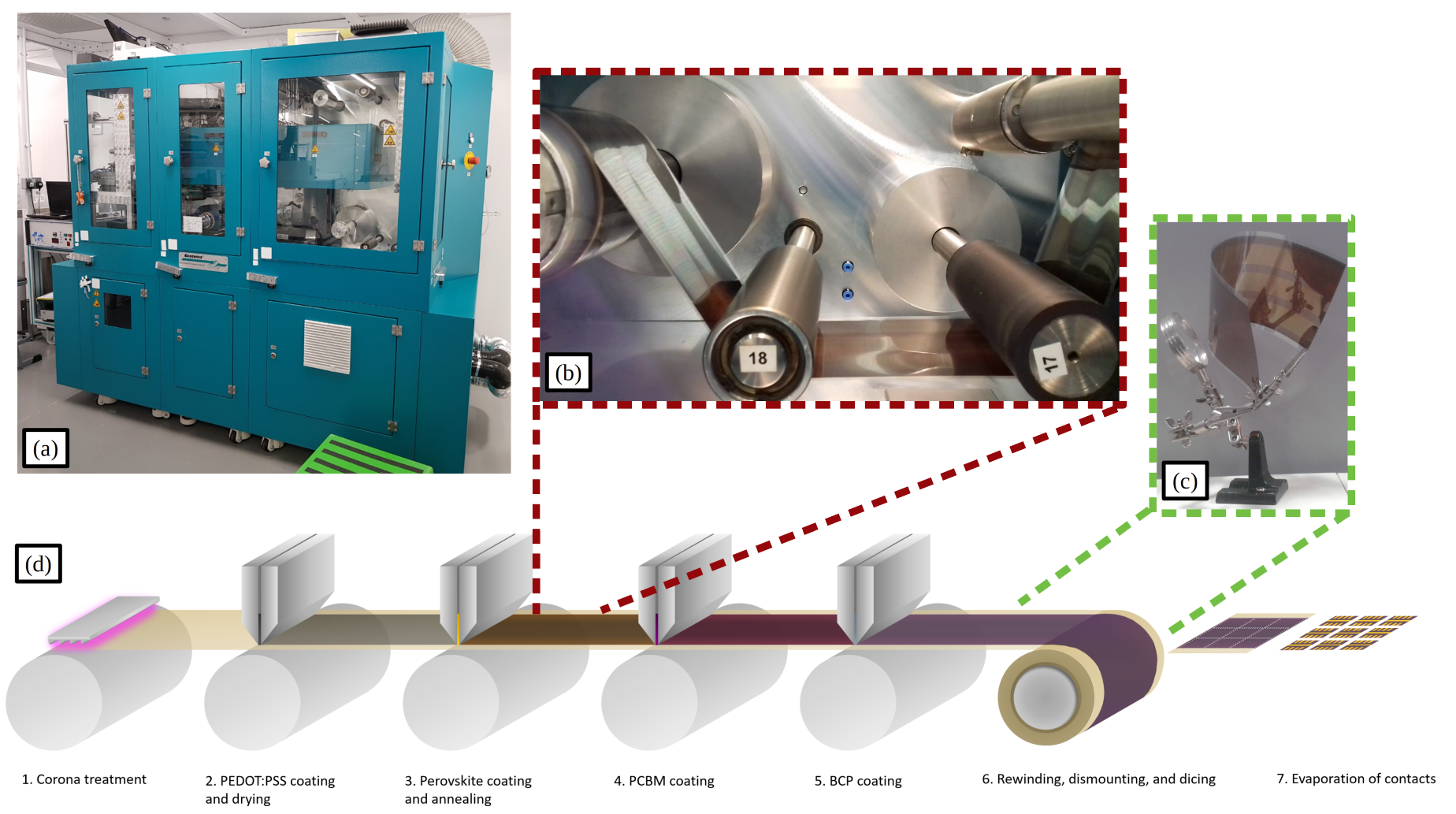

Fig. 1 The Smartcoater SC08 the R2R coatings in this work were performed with (a), R2R coated perovskite film (b), R2R coated flexible substrate with four slot-die coated layers (c) and a schematic of a fully inline coating process that the roll-to-roll slot-die coating process developments in this work could be used as part of.

The Power Conversion Efficiency (PCE) performance of perovskite solar cells and modules has risen rapidly and are now competing with the performance of conventional photovoltaic materials. The majority of these devices have been demonstrated using laboratory scale fabrication methods and demonstrating the potential for these materials to be deposited using industrially relevant deposition methods remains a little explored area, in particular for the full device stack. Several reports have been made for the use of common scalable printing and coating techniques for the deposition of some or all of the layers in the perovskite device stack, such as screen 19 and gravure printing 20 , as well as spray 21 and slot-die coating 22 . In particular screen printing is commonly used for the deposition of the 'triple mesoscopic stack' and has resulted in large area modules produced using a fabrication method that could potentially be used at an industrial level 23. But, the reports so far have been limited to batch or sheet-to-sheet (S2S) processing and not for R2R processing. Of the reports of perovskite solar cells made in part using R2R processing gravure ${ }^{20.24}$ and slot-die coating are the most commonly used deposition methods. R2R slot-die coating of the the device stack layers up to the perovskite layer has been reported for both the P-I-N ${ }^{25 \mid 26}$ and N-I-P 2728 device stack and has resulted in good device performance. Reports of R2R processing for more layers in the device stack are even fewer, both the N-I-P 2930 and P-I-N 31 device stacks have been deposited using R2R slot-die processing up to the top electrode, but in both cases evaporated top contacts have been deposited off line.

Slot-die coating leads among the current reports of R2R processed perovskite solar cell stacks. The coating method is well suited to handle a wide range of ink rheologies and is suitable for depositing low viscosity perovskite precursor inks as well as more viscous pastes. Considerable line speeds are possible with R2R slot-die coating $\sqrt{32 / 33}$ as has been demonstrated for structurally similar organic photovoltaics 34 . Slot-die coating is capable of simple pattering of films, such as stripes of material 35 |37, generally formed using shims that control where ink can flow across the coated width or block coating where the coating is usually stopped and started intermittently 43839 . These simple patterning methods can be useful for developing solar modules with interconnected devices. Slot-die coated films display several common coating defects, such as discontinuous film formation and flooding, where the deposited film is no longer continuous and uniform or ink builds up at the coating head and pre-metering is lost. The operating limits for a coating depend on the rheology of the ink used and the particular coating conditions, e.g. the coating speed and distance of the coating head lips from the substrate $32[32$.

To fully realize the benefits of a roll-to-roll process, fabrication steps must ideally be performed at the same continuous speed avoiding bottlenecks in production rate and an overall slowing of process speed or needing to perform large amounts of parallel processing. In the demonstration of a R2R printing and coat- 


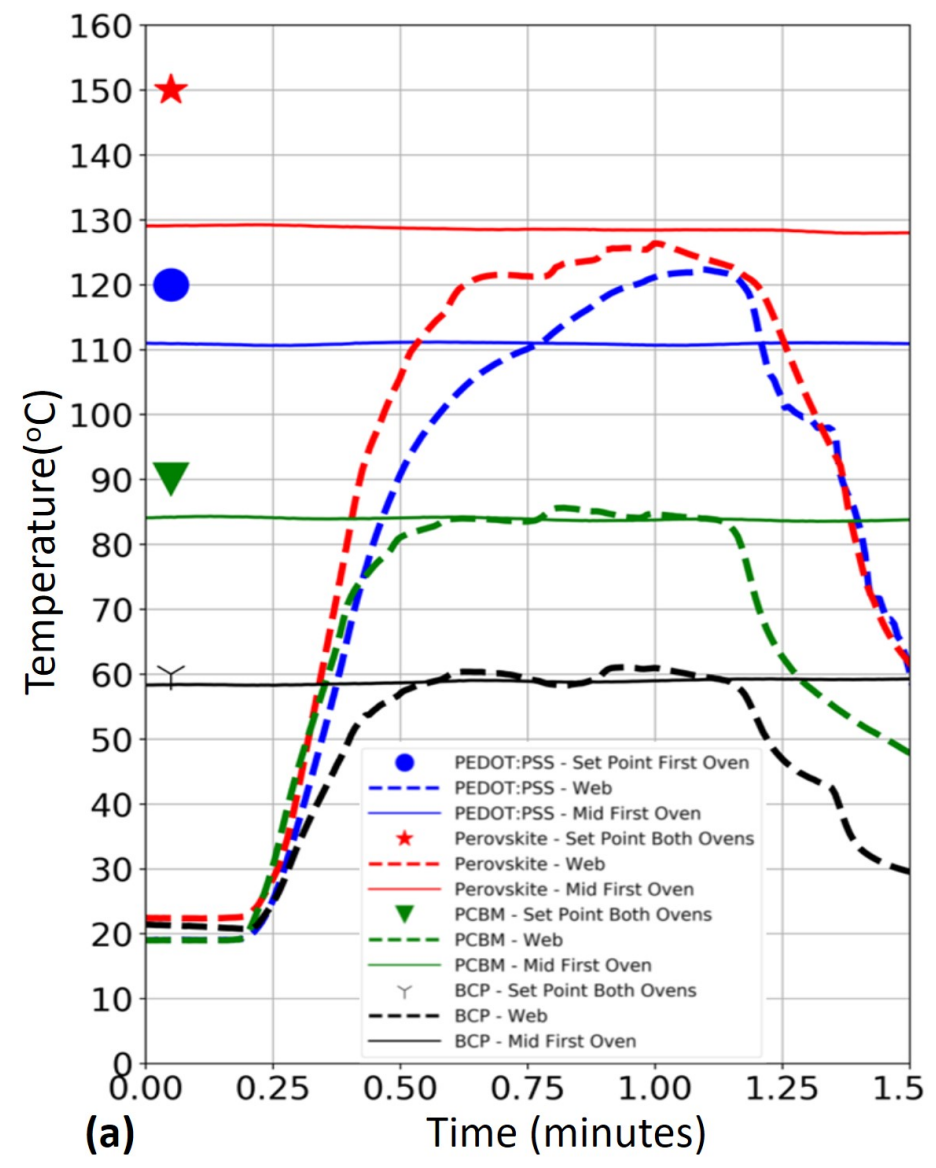

\begin{tabular}{lllll}
\hline Ink & $\begin{array}{l}\text { Surface Tension } \\
\left(\mathrm{mNm}^{-1}\right)\end{array}$ & $\begin{array}{l}\text { Viscosity } \\
(\mathrm{mPa})\end{array}$ & $\begin{array}{l}\text { Wet Film } \\
(\mu \mathrm{m})\end{array}$ & $\begin{array}{l}\text { Length } \\
(\mathrm{mm})\end{array}$ \\
\hline PEDOT:PSS & 11.77 & 22.7 & 10 & None \\
\hline Perovskite & 34 & 0.66 & 5 & 1 \\
\hline PCBM & 30 & 0.87 & 10 & 1 \\
\hline BCP & 22 & 1.28 & 7.5 & 2 \\
\hline
\end{tabular}

(b)

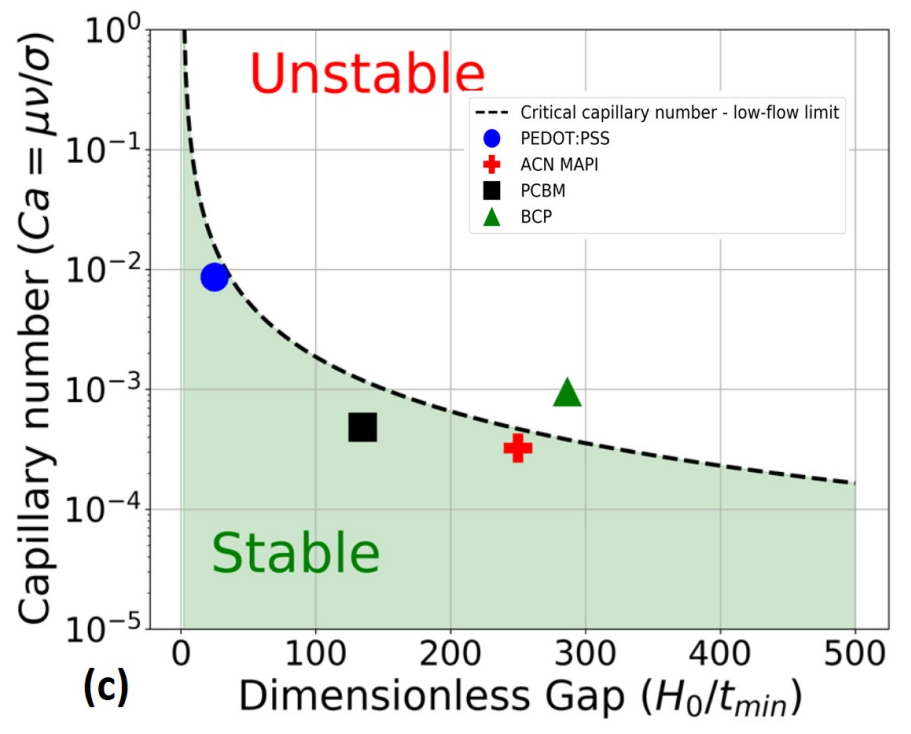

Fig. 2 Oven temperature profiles for each R2R deposited layer comparing oven set point temperatures to those measured with a thermocouple mounted in the first oven unit or attached to a bare web travelling through the oven units.(a), Rheology of slot-die coating inks and the length of the meniscus guide used with each for the optimized wet film thickness for each.(b), Capillary number vs. dimensionless gap with the critical low-flow capillary number boundary plotted and the capillary number and dimensionless gap of each ink is plotted for the coating conditions used. The capillary number is calculated as viscosity multiplied by coating speed, divided by surface tension. The dimensionless gap is the ratio of the gap between the slot-head lips and substrate to the wet film thickness, in these cases including the length covered by the meniscus guide.(c)

ing process for the fabrication of photovoltaics this entails showing that all deposition steps can be performed at a common web speed and overcoming the specific challenges that limit this in the case of each printing or coating method. With the developments in this work, the envisioned R2R process could be used as shown in Figure 1.

\section{Experimental Methods}

\subsection{Roll-to-Roll Coating}

R2R coating was performed using a Coatema Smartcoater (SC08) with a pre-patterned ITO coated PET substrate (Mekoprint OC50 $50 \Omega$ /sq sheet resistance) with $100 \mathrm{~mm}$ web width. The coater was used with a corona unit and two stage drying ovens with independently controlled temperatures and air flow rates. Temperature profiles of the oven set points used compared to the temperature read inside the oven and for a thermocouple attached to a bare web are shown in Figure 2a for the optimized drying conditions used for each layer. Details of other experimental methods are given in the Experimental Methods section of the supplementary materials.

\section{Results and Discussion}

Slot-die coating was used for the deposition of the Hole Transport Layer (HTL), perovskite active layer, Electron Transport Layer (ETL) and interlayer between ETL and top electrode. For the demonstration of a fully roll-to-roll process a common coating speed of $1 \mathrm{mmin}^{-1}$ for all layers was chosen. This was selected based on the required drying time for the perovskite layer (approximately 1 minute), that in this case was the limiting step due to the R2R coater oven length of only $1 \mathrm{~m}$. To achieve a common coating speed for these layers that have different rheologies, modification of the slot-die coating process through the use of a meniscus guide 40 (also referred to as a positive shim ${ }^{41}$ or microtip ${ }^{42}$ ) as part of the coating head was required. The rheology of the inks used is given in Figure 2b. For the lower viscosity inks coating without a meniscus guide at a given wet film thickness at $1 \mathrm{mmin}^{-1}$ resulted in flooding coating defects and a loss of pre-metering. The choice of an appropriate length meniscus guide allows the coating of these inks without flooding defects and without pushing the coating into a discontinuous film formation regime. For the more viscous PEDOT:PSS HTL ink no 
meniscus guide was required at this coating speed and wet film thickness and by setting the gap height between the coating head and substrate the film formation could be kept in a stable regime. Figure $2 c$ shows the position of the inks for the coating conditions used in relation to the low flow capillary number 43 . The gap height between the slot-die head and substrate is taken as including the length of the meniscus guide. Using these distances all the inks fall close to the low flow boundary separating stable and unstable coatings in terms of discontinuous film coating defects associated with the break-up of the downstream meniscus. Apart from the BCP ink, the inks fall within the stable region and as found in coating trials resulted in continuous film formation. The BCP ink falls just within the unstable region and is very close to the boundary and for the coatings performed was found to result in continuous film formation. Although the low-flow limit seems to apply for slot-die coating with a meniscus guide it is still poorly understood 26 . The meniscus guide length used for each ink is given in Figure $2 \mathrm{~b}$.

\subsection{Substrate and Hole Transport Layer}

For a good quality PEDOT:PSS HTL to form on the Indium Tin Oxide (ITO) coated PET substrate the film needs to be free of pin-holes and other de-wetting defects caused by poor wetting of the ink over the substrate. Formation of a good quality HTL film was made possible by using an inline corona treatment of the substrate directly before slot-die coating. The corona treatment modifies the chemistry of the substrate surface and increases the surface energy which improves wetting of the ink and reduces the number of pin-holes and de-wetting defects. It can also help remove organic contaminants from the film surface 44 . For photovoltaic devices made using treated substrate this in turn leads to fewer shunt defects and less interfacial charge recombination at the ITO electrode and so improved device performance seen predominately through increases in open circuit voltage (Voc) and Fill Factor (FF). The power of the corona treatment used was optimized by testing a range of settings, with the PEDOT:PSS HTL then slot-die coated and dried followed by dicing into device sized units (approximately $28 \times 28 \mathrm{~mm}^{2}$ ). Devices were then completed using standard spin coating and evaporation processes, these were compared to devices fabricated using spin coating of

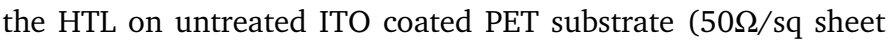
resistance ITO) and to ITO coated glass devices (using 15 $\Omega$ /sq ITO) as control devices. Table S1 shows the change in contact angle of water measured on ITO coated PET substrate with a range of corona treatment power settings $(0,0.25,0.50,0.74$ and $1 \mathrm{~kW}$ ). In all cases the corona treatment lowers the contact angle from $70^{\circ}$ to approximately $20^{\circ}$. As the power of the corona treatment was increased the device performance increased, through increases in FF and Voc. But, the highest power treatments caused damage to the ITO layer and resulted in a lowering of performance and increased spread in data. The damage to the substrate was clearly visible by eye and is shown in SEM (Scanning Electron Microscope) images in Figure S1 as areas of pitting in the main film. Current Density-Voltage (JV) scan photovoltaic performance parameter results for devices made using substrates with corona treatment power settings of $0,0.25,0.50,0.74$ and $1 \mathrm{~kW}$ are shown in Figure S2 and summarized in Table S2. The best performance was found using a corona treatment power of $0.74 \mathrm{~kW}$, which was used as substrate pre-treatment for all other coating trials discussed. The performance of the slot-die coated PEDOT:PSS layer was found to be very similar to that of spin coated devices when no corona treatment was used, showing the good quality of the layer produced and improved on this performance with the optimized power setting.

\subsection{Perovskite Layer}

Our previous work have demonstrated bench-top sheet-to-sheet (S2S) slot-die coating of $\mathrm{CH}_{3} \mathrm{NH}_{3} \mathrm{PbI}_{3}$ perovskite films from an acetonitrile/methylamine solvent mixture with $\mathrm{HCl}_{(a q)}$ chloride additive and the use of an air knife to control solvent evaporation and film uniformity 45 . In this work the same perovskite ink was used along with an air knife to produce uniform perovskite films, in a R2R coating setting. Although a short drying time of 2 minutes on a hot-plate at $140^{\circ} \mathrm{C}$ was demonstrated for this system the drying conditions using R2R hot air impingement drying is significantly different to that drying on a hot-plate with relatively low air-flow around the substrate. To determine the optimal drying conditions for the R2R slot-die coated perovskite layer a series of experiments were undertaken using different oven drying temperatures. In each case the same oven flow rate setting was used (a setting of $50 \%$ that is roughly equivalent to $45 \mathrm{~m}^{3} /$ hour) and the oven temperature varied, using the same set point for each oven stage. The oven temperatures were monitored with a thermocouple positioned near the middle of the first oven unit. A significant off set between the set point temperature and the measured temperature was found, with the offset being greater for higher set points as shown in Figure S3.

A coating speed of $1 \mathrm{mmin}^{-1}$ was used giving an oven residence time of approximately one minute. An initial batch of devices were prepared using oven set point temperatures of 120, 140, $160,190^{\circ} \mathrm{C}$ which correspond to measured oven temperatures of approximately $106,122,135$ and $150^{\circ} \mathrm{C}$. SEM images of the perovskite films formed are shown in Figure 3a. With increased drying temperature there is a compacting of the films and closing of the crystal structure. For the highest drying temperature light colored rod shaped features are visible which indicates the formation of lead iodide at the surface.

$\mathrm{XRD}$ results show that there is a shift in the main pairs of perovskite peaks near 14 and $28^{\circ}$ from lower angles to higher angle with increased drying temperature (Figure S4) and also an increase in intensity of the main 110 peak near $14^{\circ}$, as shown in Figure 3b. This indicates that the films are becoming more fully annealed with increased drying temperature.

JV scan photovoltaic performance parameter results for devices prepared using these oven settings are shown in Figure $3 \mathrm{~d}$ (more details are summarised inTable S3 and Figure S5). The $122^{\circ} \mathrm{C}$ oven temperature (set point temperature of $140^{\circ} \mathrm{C}$ ) resulted in the highest performance with a median forwards scan PCE of $12.0 \%$, which is higher than the spin coated device performance, on flexible substrates (PET-ITO sheet resistance $50 \Omega /$ sq), of $9.9 \%$ 

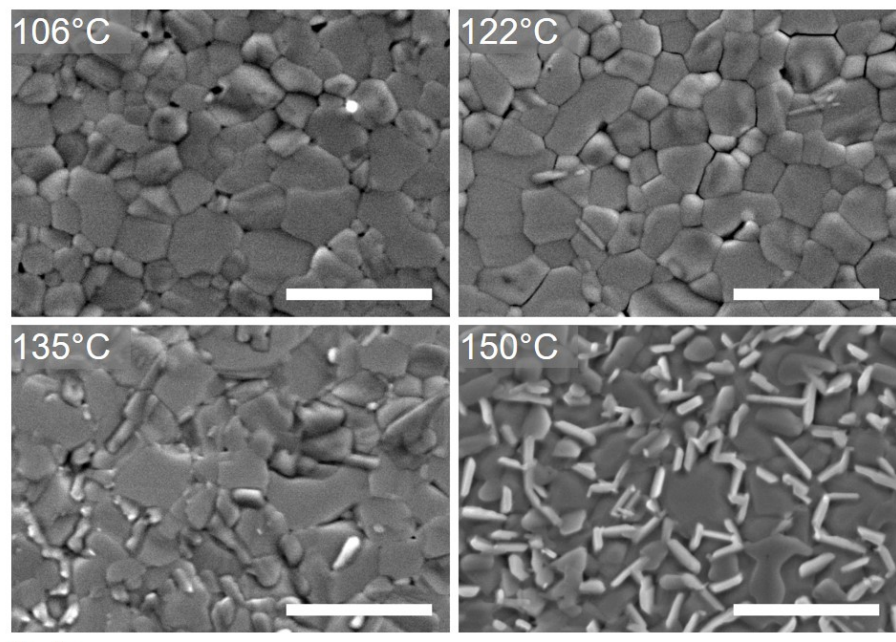

(a)

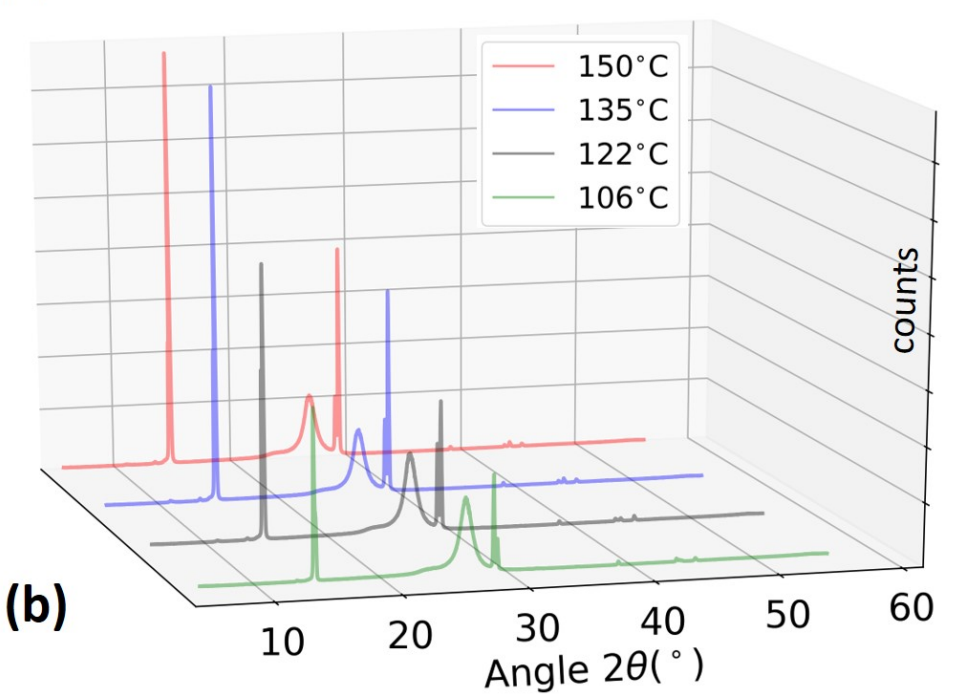

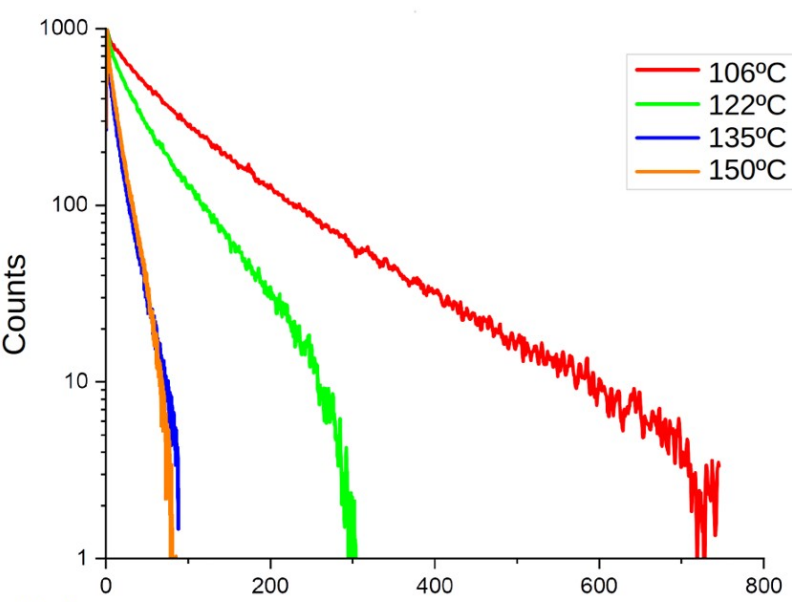

(c)

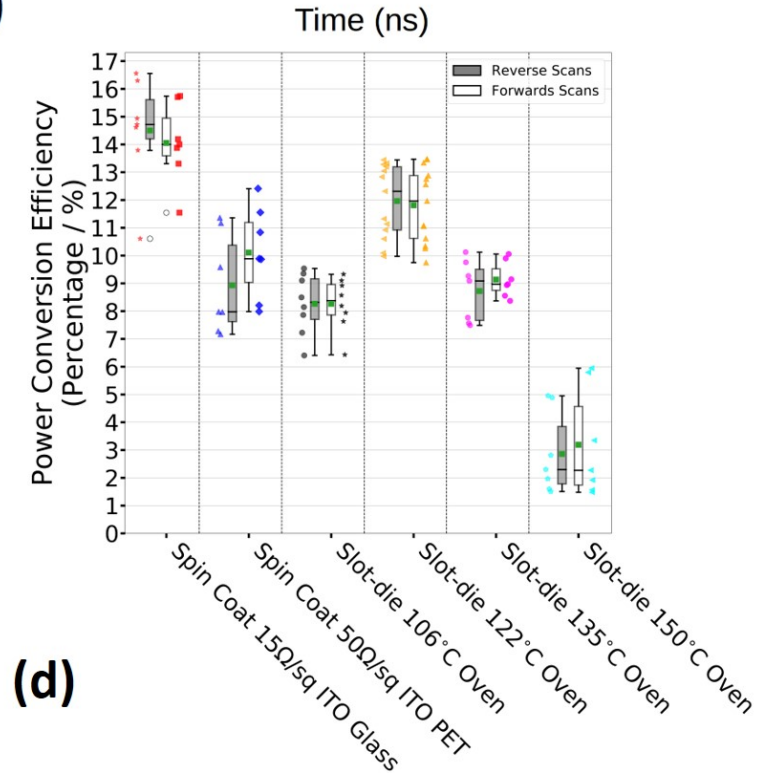

Fig. 3 Top view SEM images of $\mathrm{R} 2 \mathrm{R}$ coated perovskite films dried using various oven temperatures, $106^{\circ} \mathrm{C}\left(120^{\circ} \mathrm{C}\right.$ set point $), 122^{\circ} \mathrm{C}\left(140^{\circ} \mathrm{C}\right.$ set point), $135^{\circ} \mathrm{C}\left(160^{\circ} \mathrm{C}\right.$ set point), $150^{\circ} \mathrm{C}\left(190^{\circ} \mathrm{C}\right.$ set point). Inset scale bars represent $2 \mu \mathrm{m}$ (a). XRD spectra of R2R slot-die coated perovskite (b). Time resolved photoluminescence decay curves of perovskite films (C). Box-plots of JV scan photovoltaic PCEs for $0.09 \mathrm{~cm}^{2}$ cells with R2R slot-die coated perovskite with various drying oven temperatures compared to spin coated control devices with ITO coated PET substrates and ITO coated glass substrate control devices. The boxes represent the first and third quartiles, the horizontal black line the median, the upper whisker the data within 1.5 times the inter quartile range of the upper quartile and the lower whisker 1.5 times the inter quartile range of the lower quartile, green square the mean and open black dots outliers. The coloured full markers represent the individual scan results for the adjacent scan direction and corresponding split (d).

This demonstrates the high quality of the perovskite layer produced by R2R slot-die coating. The stabilized power output of the highest performing device was measured and resulted in a stabilized PCE of 13.5\%, as shown in Figure S6, determined from holding the cell at the maximum power point voltage and measuring the output current over the course of 50s. For the optimization of oven settings, PEDOT:PSS (as optimized in the first step) and perovskite layers were done by R2R and rest of the layers were spin coated followed by evaporation of top contact.

Time-resolved Photoluminesce (TRPL) measurements were performed on the films prepared using different drying temperatures. Longer TRPL decay lifetimes are indicative of longer charge carrier lifetimes, lower rates of non-radiative recombination and higher performing perovskite materials 14446 . TRPL mea- surements were made on the areas of substrate without ITO electrode (where extraction efficiency is expected to be lower) and illuminated with a $635 \mathrm{~nm}$ excitation pulse from the substrate side of the film and the PL yield at 770nm probed. Measurements were made at four locations spread across the coated width of the substrate and the results averaged. Normalized TRPL measurements of the films are presented in Figure 3c. Clearly the decay lifetime of the two highest drying temperatures 135 and $150^{\circ} \mathrm{C}(160$ and $190^{\circ} \mathrm{C}$ set points) are much shorter than those of the lower drying temperatures, which correlates with lower Voc $(0.95$ and $0.65 \mathrm{~V})$ of devices prepared with these films, compared to 0.98 and $0.97 \mathrm{~V}$ for the 106 and $122^{\circ} \mathrm{C}\left(120\right.$ and $140^{\circ} \mathrm{C}$ set points) dried films. Shorter carrier lifetimes and higher rates of non-radiative recombination results in a decrease in Voc. The formation of lead io- 

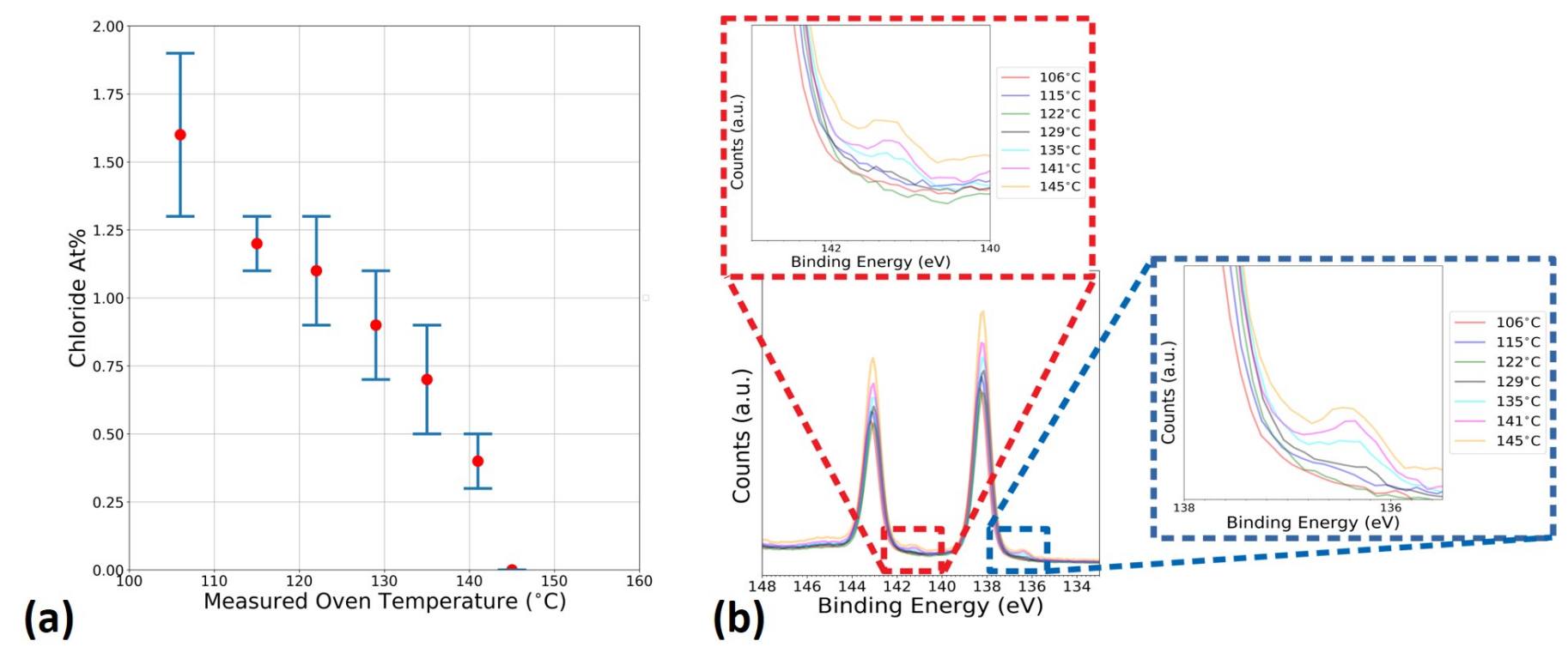

Fig. 4 : Surface chloride levels measured by $\mathrm{x}$-ray photoelectron spectroscopy for R2R slot-die coated perovskite films prepared using various different oven drying temperatures, $106^{\circ} \mathrm{C}\left(120^{\circ} \mathrm{C}\right.$ set point $), 115^{\circ} \mathrm{C}\left(130^{\circ} \mathrm{C}\right.$ set point $), 122^{\circ} \mathrm{C}\left(140^{\circ} \mathrm{C}\right.$ set point $), 129^{\circ} \mathrm{C}\left(150^{\circ} \mathrm{C}\right.$ set point $), 135^{\circ} \mathrm{C}\left(160^{\circ} \mathrm{C}\right.$ set point), $141^{\circ} \mathrm{C}\left(170^{\circ} \mathrm{C}\right.$ set point $), 145^{\circ} \mathrm{C}\left(180^{\circ} \mathrm{C}\right.$ set point $)(\mathrm{b})$. - X-ray photoelectron spectroscopy spectra showing the change in the $\mathrm{Pb} 2+4 \mathrm{f} 5 / 2$ and $4 \mathrm{f7} / 2$ and $\mathrm{PbO} 4 \mathrm{f5} / 2$ and $4 \mathrm{f7} / 2$ peaks for perovskite films R2R slot-die coated on PEDOT:PSS coated ITO coated PET substrate, at $1 \mathrm{mmin}{ }^{-1}$ from a $5 \mu \mathrm{m}$ wet film thickness, with various drying oven temperatures(b).

dide on the surface of the films would be expected to result in a higher recombination rate and faster TRPL quenching as well as a strong surface passivation effect resulting in limited charge diffusion and drop in Jsc, as seen in Figure S5. For the films prepared using the drying temperatures 106 and $122^{\circ} \mathrm{C}$ (set points of 120 and $140^{\circ} \mathrm{C}$ ) the decay lifetime is longest for the lower drying temperature and results in a similar Voc in devices. However, the overall device performance is much lower due to lower Jsc and FF, which could result from the less compact film morphology seen for the films and smaller grain-size, resulting in lower charge carrier diffusion lengths. The longer TRPL decay lifetime of the lowest drying temperature film could indicate insufficient annealing. Previously it has been shown that insufficient drying of perovskite films prepared from chloride containing precursor inks results in high levels $(>1 \%)$ of residual chloride and also that locally high levels of chloride in perovskite films have been shown to result in longer decay lifetimes ${ }^{46}$. This suggests that the cause of the longer decay lifetime found for the lowest drying temperature is a result of high levels of residual chloride and that the films prepared at this drying temperature might not be fully annealed, which is supported by the device performance data, as well as the XRD and SEM results.

Further optimization of the drying conditions were made in the range of set-point temperatures around $140^{\circ} \mathrm{C}$, with device performance results shown in Figure S7 and summarized in Table S4. The optimal device performance was found for a drying temperature of $129^{\circ} \mathrm{C}$ with a set-point of $150^{\circ} \mathrm{C}$. The general performance of devices was lower than for the previous batch, as seen for the results of spin coated control devices on glass substrate, which was attributed to lower quality perovskite solution.

The higher temperature drying conditions again result in the formation of lead iodide as shown in XRD spectra, Figure S8. SEM images, Figure $S 9$, shows similar trend of thermal degradation at higher temperatures.

To further study the drying conditions $\mathrm{x}$-ray photoelectron spectroscopy (XPS) was employed to analyse the surface chemistry of the films. Previously it was shown that to achieve the best device performance the chloride level in films must be reduced to the region of around $1 \%$ and that some residual chloride at around $0.5-1 \%$ is beneficial to device performance. Figure S10 shows XPS spectra of the films with different drying temperatures and the region of binding energies (204-194eV) associated with typical chloride $\mathrm{Cl} 2 \mathrm{p}_{3 / 2}$ and $\mathrm{Cl} 2 \mathrm{p}_{1 / 2}$ peak positions. The films dried with the lowest temperature $\left(106^{\circ} \mathrm{C}\right.$, set point $\left.120^{\circ} \mathrm{C}\right)$ show distinct peaks and indicate there is substantial residual chloride in the surface of these films. For higher drying temperatures the intensity of these peaks decreases and for the highest drying temperature $\left(145^{\circ} \mathrm{C}\right.$, set point $\left.180^{\circ} \mathrm{C}\right)$ the peaks are no longer present, indicating that chloride has been completely removed from the surface of the films. Figure 4a shows the level (in terms of atomic \%) of chloride found in the films depending on the drying temperature used. With the optimized drying temperature of $\left(129^{\circ} \mathrm{C}\right.$, set point $150^{\circ} \mathrm{C}$ ) resulting in a surface chloride level of $0.9 \%$, which is similar to the level $0.6 \%$ found for optimized spin coated devices on glass (dried on hot-plate) using the same perovskite ink. XPS spectra of the regions of binding energies (148-133eV) associated with $\mathrm{Pb}^{2+} 4 \mathrm{f}_{5 / 2}$ and $4 \mathrm{f}_{7 / 2}$ is given in Figure $4 \mathrm{~b}$. For the highest drying temperatures $\left(135,141\right.$, and $145^{\circ} \mathrm{C}$, set points of 160,170 and $180^{\circ} \mathrm{C}$ ) secondary peaks centered around 141.8 and $136.8 \mathrm{eV}$ are present that are assigned to $\mathrm{Pb}^{0} 4 \mathrm{f}_{5 / 2}$ and $4 f_{7 / 2}$, this further indicates damage and degradation of the perovskite surface for the higher drying temperatures. 
Results of R2R coated perovskite with the same optimized coating and drying $\left(129^{\circ} \mathrm{C}, 150^{\circ} \mathrm{C}\right.$ set point) conditions made as part of 10 different batches across six months are shown in Figure S11. Across all these devices a median forwards JV scan PCE of 9.2\% was achieved. Across the different batches of devices there was some performance variation that was attributed to the quality of the perovskite ink used and in part due to the particular production lots of lead iodide used and possible contamination of these reported by the supplier after purchase. Nonetheless, these results demonstrate that high performance R2R perovskite films can be successfully fabricated and that the acetonitrile/methylamine solvent system ink is suitable for R2R slot-die coating. The optimized oven drying setting, $129^{\circ} \mathrm{C}$, set point of $150^{\circ} \mathrm{C}$, was used for all further R2R coatings.

\subsection{Electron Transport Layer and Inter Layer}

PCBM can be oxidized in the presence of light and air, since the coating process is carried out under ambient conditions both these factors are present and the film could degrade, in particular when being dried at elevated temperatures with a large flux of air passing over the film. To give an indication of the stability of the PCBM layer to drying in air and what drying conditions should be used for the PCBM layer, spin coated devices were prepared and the PCBM layer dried on a hot-plate in air at room temperatures of $60,80,100$ and $120^{\circ} \mathrm{C}$ for 5 minutes and compared to films with no drying. No significant difference was found in device results for the drying conditions, Figure S12 and Table S5. Given these results, an initial drying temperature of approximately $80^{\circ} \mathrm{C}$ was used for devices prepared using slot-die coated films.

Chlorobenzene has been successfully used for slot-die coating of PCBM layers in perovskite solar cells but when moving to a larger scale process poses several challenges. The low Workplace Exposure Limit (WEL) of chlorobenzene (UK Time Weighted Average (TWA) 1ppm) means only small volumes can be used without breaching safe usage limits or using rigorous and expensive containment and monitoring methods. The environmental impact of chlorinated solvents is also a disadvantage to use at scale. As an alternative to chlorobenzene, toluene was investigated as solvent for PCBM due to its higher WEL TWA of 50ppm. Scanned images of films, deposited on bare PET substrate (both inks wet the substrate fully and wet perovskite films fully), slot-die coated using formulations of PCBM $10 \mathrm{mgml}^{-1}$ in either solvent are shown in Figure S13. The film deposited from the toluene based ink shows poor macro uniformity compared to that deposited from the chlorobenzene based ink. The uniformity of the films was further analyzed using white light interferometry, the roughness of the surfaces was characterized using the Sa parameter (arithmetic mean of the areal absolute height). Over a small areas (x50 magnification, $94 \times 125 \mu \mathrm{m}$ ) the roughness values for both films are similar (13 and $16 \mathrm{~nm}$, Figure $5 \mathrm{~b}$ ). Over a larger area the non-uniformity of the toluene film is more apparent, Figure $5 \mathrm{a}$ shows the topology of a $10 \times 10 \mathrm{~mm}$ area of the film, showing the macro-scale non-uniformity of the film.

Devices prepared with the toluene PCBM formulation resulted in poor device performance compared to those prepared using chlorobenzene, as shown in Figure S14 and Table S6. The evaporated silver top electrodes also rapidly showed signs of degradation and the perovskite film in the areas covered by the silver electrode became yellow coloured at a faster rate than the chlorobenzene film devices. Silver electrodes rapidly degrade if in direct contact with perovskite due to the reactive nature of iodide ions and silver. The non uniform film formation of the PCBM layer deposited from toluene leaves pin-holes and voids where the silver electrode can directly contact the perovskite and cause degradation to the electrode and perovskite material and the poor uniformity of the layer is a poor barrier to iodide migration from the perovskite to the silver electrode.

To further investigate the drying profile of the inks simultaneous thermal analysis (STA) was employed, Figure $5 \mathrm{c}$ and $5 \mathrm{~d}$ shows the weight and heatflow profiles of the chlorobenzene and toluene formulations, during a temperature ramp of $10^{\circ} \mathrm{C}$ per minute. The total evaporation of solvent was determined as the point at which the mass derivative with respect to time equals zero. For toluene complete solvent evaporation occurred by $83^{\circ} \mathrm{C}$ compared to $105^{\circ} \mathrm{C}$ for chlorobenzene. This plateau in the weight curve is preceded by an endothermic peak in the heatflow signal at $74^{\circ} \mathrm{C}$ for toluene and $102^{\circ} \mathrm{C}$ for chlorobenzene. As these maxima occur before the corresponding weight plateau, they are due to solvent evaporation. The rapid drying of the toluene ink is characterised by a steep weight-loss with an abrupt plateau and a broad flat-topped endothermic peak that indicates a relatively long time close to the maximum rate of evaporation. This causes uneven drying and non-uniformity in the coated samples resulting in the mottled appearance shown in Figure S13 that is not seen for the other solvent systems.

To develop a more suitable solvent system, blends of multiple solvents were investigated. Firstly the addition of O-xylene was investigated as a binary solvent mixture with toluene. Oxylene is less volatile (boiling point $144^{\circ} \mathrm{C}$ ) than toluene and showed improved solubility for PCBM 47 , with an ink prepared using a 7:3vol/vol ratio of toluene:O-xylene. Along with this, ternary solvent blends with toluene and $\mathrm{O}$-xylene in a $6: 3 \mathrm{v} / \mathrm{v}$ ratio along with 1 part of a higher boiling point solvent, with good solubility for PCBM, were investigated. The chosen higher boiling point solvents; cyclohexanone $\frac{47}{4}$ (boiling point $156^{\circ} \mathrm{C}$ ), 2 methylanisole ${ }^{48}\left(171^{\circ} \mathrm{C}\right)$ and indan $49\left(182^{\circ} \mathrm{C}\right)$. The STA analysis for the toluene: $\mathrm{O}$-xylene only ink shows a small increase in point of complete solvent evaporation $\left(85^{\circ} \mathrm{C}\right)$, for the ink with cyclohexanone this increases to $89^{\circ} \mathrm{C}, 2$-methylanisole $91^{\circ} \mathrm{C}$ and indan $105^{\circ} \mathrm{C}$, Figure $5 \mathrm{c}$. The heatflow peaks, corresponding to the maximum rate of solvent evaporation, follow the same upward shift with the addition of the higher boiling solvent.

The rheology of the different inks is given in Table S7, with all the inks being relatively similar and so expected to have similar slot-die coating stability. Images of PCBM films coated using the various inks are shown in Figure S13. The ink with a blend of toluene:O-xylene shows improved slot-die coating macro film uniformity compared to the toluene only film. The film from the ink with the addition of cyclohexanone shows reasonable macro slot-die coating uniformity. But, the surface roughness as indicated by the Sa parameter (Figure 5b), is much higher than for 


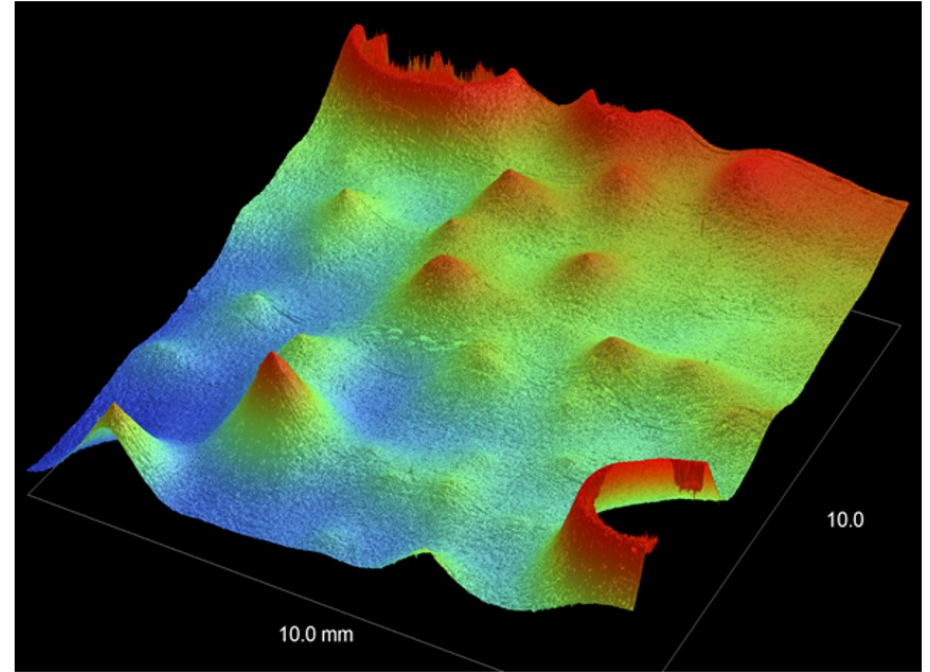

(a)

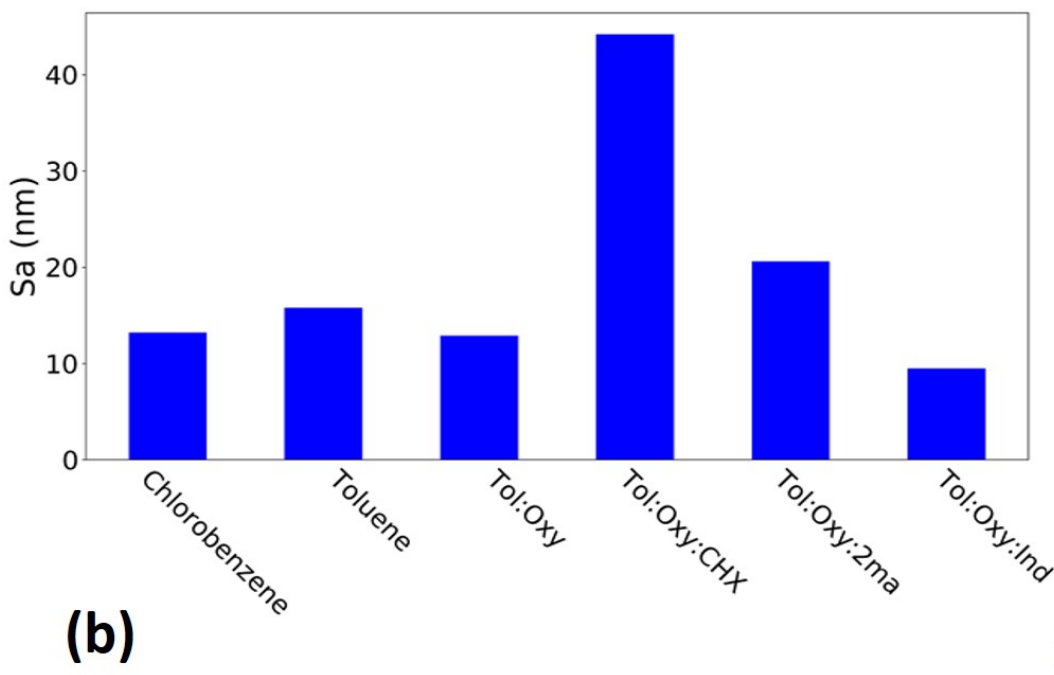

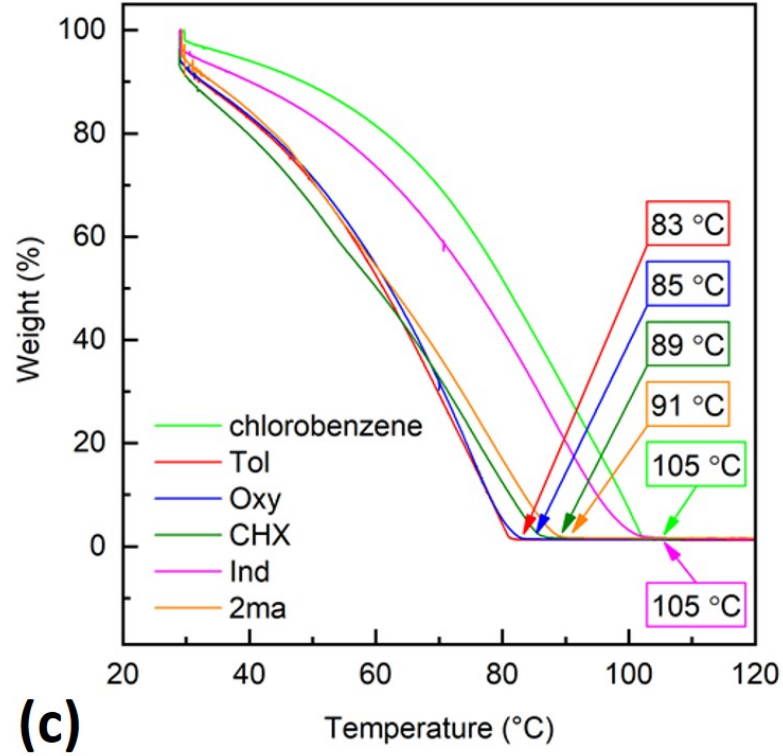

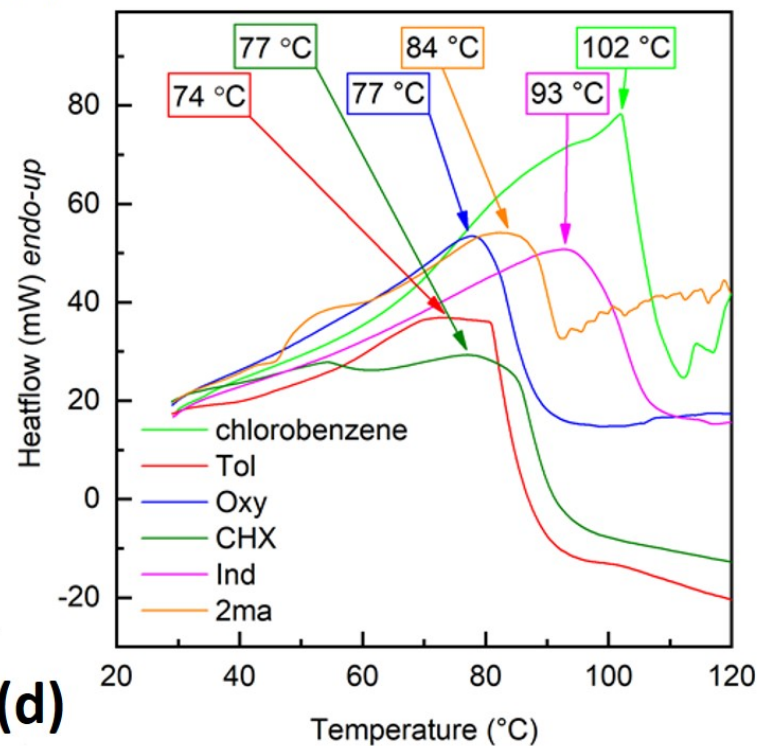

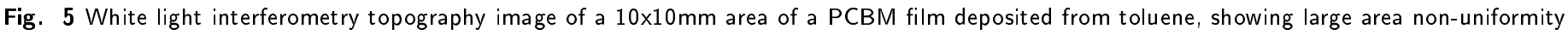

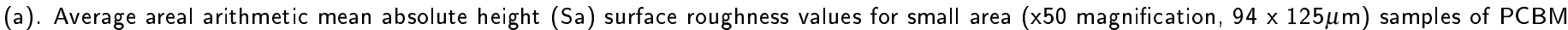

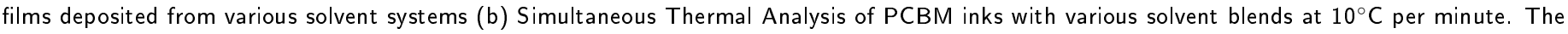

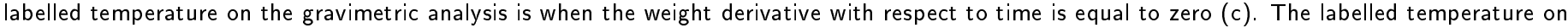

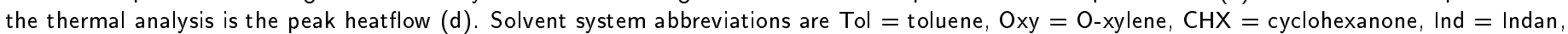
$2 \mathrm{ma}=2$-methylanisole.

the other solvent systems, suggesting the PCBM is aggregating as it dries. This is supported by the heatflow curve (Figure 5d)from the STA analysis showing two broad peaks that indicate a steady rate of solvent evaporation over a wide temperature range. The continued mobility of the PCBM in the film as it dries provides opportunity for aggregation to occur. The inks with the addition of 2-methylanisole or indan show good macro slot-die coating uniformity and surface roughness similar to that of films prepared with the chlorobenzene ink. The ink containing an addition of 2-methylanisole shows a clear three-stage profile in the heatflow signal, this gradual solvent removal reduces PCBM mobility as the film dries. And the complete solvent removal by $91^{\circ} \mathrm{C}$ of- fers a clear improvement over chlorobenzene when considering both workplace-exposure and high-throughput processing. Devices were prepared using the various PCBM inks, with the PCBM layer S2S slot-die coated on a desk top coater on to R2R coated perovskite stack substrates. The device JV scan photovoltaic performance parameters are summarized in Figure S14. The devices prepared with the ink with addition of cyclohexanone show poor performance, mainly due to low Jsc, as would be expected from the poor morphology and high surface roughness found for the coatings. The devices prepared using the ink with addition of indan show very poor performance, despite the good film formation, this is due to very low Jsc and FF. The cause of the poor per- 
formance is unclear, there was no visible damage to the perovskite film caused by the solvent. The low volatility of the solvent may have resulted in residual solvent still being present in the films after the relatively short and low temperature drying process. Devices prepared with the ink with addition of 2-methylanisole showed excellent device performance equal to that of films deposited from chlorobenzene, this ink was used for further R2R optimizations of the PCBM layer.

Further optimization of the PCBM film thickness was carried out with R2R slot-die coating. JV scan photovoltaic performance parameter results for devices prepared using wet film thicknesses of 5, 7.5, 10 and $12.5 \mu \mathrm{m}$ are summarized in Table S8 and shown in Figure S15. These correspond to dry film thicknesses of approximately 40, 60, 80 and 100nm, from profilometry measurements. The device performance increases with increasing film thickness, in particular the forwards scan Voc increases from $0.80 \mathrm{~V}$ to $0.93 \mathrm{~V}$, but for the thickest $12.5 \mu \mathrm{m}$ wet film thickness the series resistance increases and FF begins to decrease. The spin coated and slot-die coated $5,7.5,10$ and $12.5 \mu \mathrm{m}$ wet film thicknesses resulting in forwards scan series resistance of 7.0, 6.7, 7.5, 8.7 and $9.3 \Omega \cdot \mathrm{cm}^{2}$ respectively. The optimized film thickness determined to be from a $10 \mu \mathrm{m}$ wet film thickness which corresponds to an approximately $80 \mathrm{~nm}$ dry film thickness, which is similar to the optimized spin coated dry film thickness of approximately 70nm. The $10 \mu \mathrm{m}$ wet film thickness was used for all further PCBM coatings.

Further analysis of the optimized PCBM layer was carried out using XPS, to determine if any degradation of the surface layer had occurred. This would be expected to be indicated by oxidation of the PCBM molecules and an increase in the oxygen levels detected in the film 50 . Two main $\mathrm{O}(1 \mathrm{~s})$ features due to the ether like and carbonyl oxygen atoms in the ester group of the PCBM side chain are expected to be present in the XPS spectra in the region of $532 \mathrm{eV}$, as was found and is shown in Figure S16. The expected level of oxygen for a pristine PCBM layer would be 2.7 atomic \% and for the R2R coated samples was found to be 4.6 atomic \%, summarized in Table S9. This shows that only limited oxidation of the film was detected and the film was of good quality and not unduly damaged by the coating and drying conditions used.

The stability of films prepared using the different PCBM wet film thicknesses was monitored through time lapse photography of complete devices stored in a light box in ambient conditions, with photographs taken at regular intervals, as shown in Figure S17. By the end of the tests there are visible signs of degradation for all layer thicknesses and the spin coated PCBM control films. This is noticeable from the films appearing yellow, the degradation process starts at the areas of film under the edges of the silver electrode and progressively moves towards the center of the area covered by the top electrode. Silver electrodes have been shown to degrade through reaction with mobile iodide ions from perovskite layers and that silver ions from the electrode can migrate into the perovskite and cause degradation ${ }^{51 / 52}$. The initial degradation of the layers at the areas covered by the edges of the electrodes suggests that the degradation process is accelerated by moisture and/or oxygen, as the silver layer is expected to be a reasonable barrier to oxygen and moisture and that the degradation process is through a combination of silver electrode and perovskite ${ }^{53}$. The devices prepared using thinner layers of PCBM show more rapid signs of degradation, suggesting that the PCBM layer acts to inhibit silver ion or iodide ion migration, as found in other studies 52 . Comparing the rates of degradation to the spin coated films, the slot-die films prepared with $10 \mu \mathrm{m}$ wet film thickness (approximately 80nm dry film thickness) show a similar rate. The thicker film a slower rate and the thinner films more rapid, as would be expected from the relative dry film thicknesses of each layer. This also demonstrates that the optimized thickness slot-die coated films have good uniformity compared to those produced by spin coating (approximately 70nm film thickness) and degrade at a similar rate.

Bathocuproine (BCP) is commonly used as an interface layer between the PCBM layer and top electrode in perovskite solar cells. It has been reported to reduce interfacial charge recombination, create a more ohmic contact between the PCBM and top electrode layers and improve device performance and stability 54 . Deposition of BCP layers by both evaporation and solution processing methods have been reported. Solution processed BCP layers have been suggested to help 'smooth' and planarise the interface between perovskite, PCBM and the top electrode 5 . The optimal film thickness is reported as only around $5 \mathrm{~nm}^{[54[54}$ which is challenging for uniform large area deposition.

To optimize the BCP layer deposited by R2R slot-die coating a range of wet film thicknesses were trialed, between 5 and $15 \mu \mathrm{m}$, using a dilute solution of BCP in ethanol $\left(0.5 \mathrm{mgml}^{-1}\right)$. The films were dried in the coating machine inline ovens with a low temperature of approximately $58^{\circ} \mathrm{C}$ (set point $=60^{\circ} \mathrm{C}$ ). To determine if the BCP was present on the PCBM layer surface after coating, XPS was used to investigate the surface chemistry. BCP molecules can be characterized by a N1s peak in the XPS spectra ${ }^{56}$. Figure S18 shows that for all wet film thicknesses used there is a significant increase in the N1s peak near $398 \mathrm{eV}$. The PCBM only film, shown also in detail Figure S19, shows only a small N1s signal. The origin of which could be nitrogen atoms associated with the perovskite methylammonium groups. A small secondary peak near $401 \mathrm{eV}$ is also present for all wet film thicknesses used, which is ambiguous to assign but could be due to shifted to a higher binding energy due to a loss of electron density through oxidation or electron donation as a ligand 57 . These results confirm that for all wet film thicknesses BCP is detectable on the PCBM surface and no significant degradation to the BCP molecules is detected. In all cases the atomic \% of nitrogen (0.37-0.89\%), Table S9, indicates that a complete and continuous BCP layer is not formed, that would be indicated by a nitrogen level of 7 atomic $\%$, or the layer is thinner than the detectable level and possibly a monolayer has formed. Device JV scan photovoltaic parameters are summarized in Figure S20 and Table S10, the optimal wet film thickness was found to be $7.5 \mu \mathrm{m}$. With greater wet film thicknesses resulting in devices with increased series resistance and reduced FF and lower PCEs. Devices prepared using the optimized wet film thickness resulted in good performance with a median PCE of $9.7 \%$ and a hero cell performance of $12.2 \%$, stabilised power output of the hero device are given in Figure 6 with a stabilised PCE of $12 \%$ 
for devices prepared with all layers, other than the top contact, prepared using R2R deposition methods.

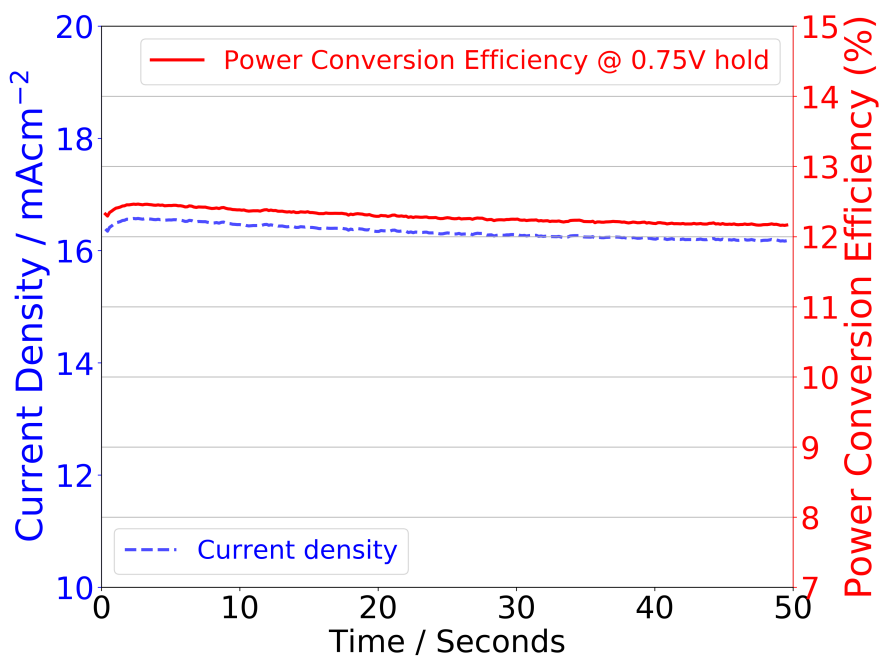

Fig. 6 Stabilized power output of R2R coated hero cell held at maximum power point voltage, with $H C L$, perovskite, ECL and interlayer R2R slotdie coated.

The stability of films prepared using the different BCP wet film thicknesses was monitored through time lapse photography of complete devices stored in a light box in ambient conditions over the course of 8 days, with photographs taken at regular intervals, as shown in Figure S21. The slot-die coated devices prepared with thicker BCP wet film thicknesses degrade slower than those prepared with thinner wet film thicknesses. Compared to those prepared with a spin coated BCP layer the devices prepared with the thinnest wet film thickness degrade at a similar rate and the thicker films slightly slower. Simple analysis of the color intensity of the images in the device areas over time shows the trend in Figure S22. Red color channel of the RGB image was selected and the average color intensity of the pixels within the device areas calculated for each split and the change from the initial values over time determined. The non-degraded films color is predominately due to the perovskite, which results in a low red channel color intensity and the degraded films appear yellow, which result in a higher intensity 58 . From this analysis it is evident that the spin coated BCP layer on slot-die coated PCBM degrades to a greater extent than the slot-die coated BCP layers on slot-die coated PCBM films. This shows that the slot-die coating process results in a BCP and PCBM interface that is improved compared to the spin coated BCP layer in terms of degradation stability.

To further test the stability of devices dark shelf life tests were made with devices with spin coated PCBM and BCP or slot-die coated PCBM and BCP stored in the dark in a nitrogen filled glovebox and periodically removed and tested over the course of 6 days. The JV scan photovoltaic parameters recorded are shown in Figure S23, there is a gradual drop in efficiency to approximately $90 \%$ and $88 \%$ respectively from the initial values, indicating the slot-die coated PCBM and BCP layers are no less stable than the spin coated layers.

\section{Conclusions}

This work demonstrates a R2R fabrication process for P-I-N stack perovskite solar cells with all layers apart from the electrode deposited using R2R slot-die coating. A common coating speed of $1 \mathrm{mmin}^{-1}$ was used for all layers and demonstrates the potential to transfer to a fully inline process. This is made possible through consideration of the rheology of each ink used and selection of an appropriate length meniscus guide to achieve a stable coating without flooding or discontinuous film formation.

The use of a perovskite ink based on an acetonitrile/methylamine solvent mixture with the addition of $\mathrm{HCl}_{(a q)}$ and the application of an air-knife to control the initial drying profile of the films was demonstrated for R2R slot-die coating. The annealing conditions for the layer were found to be critical for device performance and were optimized and analyzed using XPS, XRD, SEM and PL. An alternative solvent system for slotdie coating of PCBM was developed and avoided the use of the commonly used and highly toxic chlorobenzene. Through judicious choice of blends of solvents with a range of volatilities a mixture of toluene, $\mathrm{O}$-xylene and 2-methylanisole in a 6:3:1 ratio was found to give good film quality and device performance equal to that of chlorobenzene for slot-die coating. The layer was further optimized in R2R slot-die coatings and resulted in devices with good performance and device stability similar to that of spin coated PCBM from chlorobenzene.

Finally R2R slot-die coating of a BCP interface layer on top of PCBM was demonstrated and the wet film thickness for slotdie coating optimized and resulted in devices with good average performance and a stabilised PCE of $12.2 \%$. This is the highest reported to date for devices with all layers other than the top electrode deposited R2R.

In a broader context this work helps to further demonstrate the potential for R2R manufactured photovoltaics to achieve significant device performances, that coupled with improved stability and lifetimes of materials could create a genuine alternative solar energy technology. In the case of lead containing perovskite photovoltaics, deployment of large format roll-on-roll-off modules, made possible through R2R processing (as demonstrated for organic photovoltaics ${ }^{7}$ ) may help to generate a closed loop for production, deployment, operation and decommissioning. This could help reduce the chances of the uncontrolled release of lead into the environment, increased reuse and recycling rates and so reduce costs for the Bill of Materials, speed and simplify deployment and decommissioning and so reduce the Balance of Systems costs, which could further improve the economic viability of the technology and possibly help mitigate the problems associated with the current short lifetime of perovskite devices.

\section{Acknowledgments}

This work is part funded by the European regional Development Fund through the Welsh Government and was supported by the Engineering and Physical Sciences Research Council (EPSRC) through the SPECIFIC Innovation and Knowledge Centre (EP/N020863/1) and Self-assembling Perovskite Absorbers Cells Engineered into Modules project (EP/M015254/2). This 
project has received funding from the European Union Horizon 2020 research and innovation programme under the Marie Sklodowska-Curie grant agreement No 764787. The authors would like to acknowledge the financial support provided by the M2A that has been made possible through funding from the European Social Fund via the Welsh Government, the Engineering and Physical Sciences Research Council (EP/L015099/1) and Tata Steel Europe that has made this research possible. We would like to acknowledge the assistance provided by Swansea University College of Engineering AIM Facility, which was funded in part by the EPSRC (EP/M028267/1), the European Regional Development Fund through the Welsh Government (80708) and the Ser Solar project via Welsh Government. MD, SD and MC are grateful for financial support from Edinburgh Instruments.

\section{References}

1 T. Tsujimura, J. Fukawa, K. Endoh, Y. Suzuki, K. Hirabayashi and T. Mori, Journal of the Society for Information Display, 2014, 22, 412-418.

2 R. Søndergaard, M. Hösel, D. Angmo, T. T. Larsen-Olsen and F. C. Krebs, Materials Today, 2012, 15, 36 - 49.

3 J. Sun, H. Park, Y. Jung, G. Rajbhandari, B. B. Maskey, A. Sapkota, Y. Azuma, Y. Majima and G. Cho, ACS Omega, 2017, 2, 5766-5774.

4 R. Abbel, I. de Vries, A. Langen, G. Kirchner, H. t'Mannetje, H. Gorter, J. Wilson and P. Groen, Journal of Materials Research, 2017, 32, 2219-2229.

5 A. Sandström and L. Edman, Energy Technology, 2015, 3, 329339.

6 P. Sommer-Larsen, M. Jørgensen, R. R. Søndergaard, M. Hösel and F. C. Krebs, Energy Technology, 2013, 1, 15-19.

7 F. C. Krebs, N. Espinosa, M. Hösel, R. R. Søndergaard and M. Jørgensen, Advanced Materials, 2014, 26, 29-39.

8 R. R. Søndergaard, N. Espinosa, M. Jørgensen and F. C. Krebs, Energy Environ. Sci., 2014, 7, 1006-1012.

9 N. Espinosa, M. Hösel, M. Jørgensen and F. C. Krebs, Energy Environ. Sci., 2014, 7, 855-866.

10 Z. Song, C. L. McElvany, A. B. Phillips, I. Celik, P. W. Krantz, S. C. Watthage, G. K. Liyanage, D. Apul and M. J. Heben, Energy Environ. Sci., 2017, 10, 1297-1305.

11 N. L. Chang, A. W. Y. Ho-Baillie, D. Vak, M. Gao, M. A. Green and R. J. Egan, Solar Energy Materials and Solar Cells, 2018, 174, $314-324$.

12 D. B. Mitzi, S. Wang, C. A. Feild, C. A. Chess and A. M. Guloy, Science, 1995, 267, 1473-1476.

13 A. Kojima, K. Teshima, Y. Shirai and T. Miyasaka, Journal of the American Chemical Society, 2009, 131, 6050-6051.

14 S. D. Stranks, G. E. Eperon, G. Grancini, C. Menelaou, M. J. P. Alcocer, T. Leijtens, L. M. Herz, A. Petrozza and H. J. Snaith, Science, 2013, 342, 341-344.

15 G. Xing, N. Mathews, S. Sun, S. S. Lim, Y. M. Lam, M. Grätzel, S. Mhaisalkar and T. C. Sum, Science, 2013, 342, 344-347.

16 S. D. Stranks, ACS Energy Letters, 2017, 2, 1515-1525.

17 M. M. Lee, J. Teuscher, T. Miyasaka, T. N. Murakami and H. J. Snaith, Science, 2012, 338, 643-647.
18 F. D. Giacomo, S. Shanmugam, H. Fledderus, B. J. Bruijnaers, W. J. Verhees, M. S. Dorenkamper, S. C. Veenstra, W. Qiu, R. Gehlhaar, T. Merckx, T. Aernouts, R. Andriessen and Y. Galagan, Solar Energy Materials and Solar Cells, 2018, $181,53-59$.

19 A. Mei, X. Li, L. Liu, Z. Ku, T. Liu, Y. Rong, M. Xu, M. Hu, J. Chen, Y. Yang, M. Grätzel and H. Han, Science, 2014, 345, 295-298.

20 Y. Y. Kim, T.-Y. Yang, R. Suhonen, M. Välimäki, T. Maaninen, A. Kemppainen, N. J. Jeon and J. Seo, Advanced Science, 2019, 6, 1802094.

21 J. E. Bishop, T. J. Routledge and D. G. Lidzey, The Journal of Physical Chemistry Letters, 2018, 9, 1977-1984.

22 R. Patidar, D. Burkitt, K. Hooper, D. Richards and T. Watson, Materials Today Communications, 2019, 100808.

23 F. De Rossi, J. A. Baker, D. Beynon, K. E. A. Hooper, S. M. P. Meroni, D. Williams, Z. Wei, A. Yasin, C. Charbonneau, E. H. Jewell and T. M. Watson, Advanced Materials Technologies, 2018, 3, 1800156.

24 C. Gong, S. Tong, K. Huang, H. Li, H. Huang, J. Zhang and J. Yang, Solar RRL, 0, 1900204.

25 C. Zuo, D. Vak, D. Angmo, L. Ding and M. Gao, Nano Energy, 2018, 46, 185 - 192.

26 D. Burkitt, P. Greenwood, K. Hooper, D. Richards, V. Stoichkov, D. Beynon, E. Jewell and T. Watson, MRS Advances, 2019, 4, 1399-1407.

27 Y. Galagan, F. Di Giacomo, H. Gorter, G. Kirchner, I. de Vries, R. Andriessen and P. Groen, Advanced Energy Materials, 2018, 8, 1801935.

28 B. Dou, J. B. Whitaker, K. Bruening, D. T. Moore, L. M. Wheeler, J. Ryter, N. J. Breslin, J. J. Berry, S. M. Garner, F. S. Barnes, S. E. Shaheen, C. J. Tassone, K. Zhu and M. F. A. M. van Hest, ACS Energy Letters, 2018, 3, 2558-2565.

29 K. Hwang, Y.-S. Jung, Y.-J. Heo, F. H. Scholes, S. E. Watkins, J. Subbiah, D. J. Jones, D.-Y. Kim and D. Vak, Advanced Materials, 2015, 27, 1241-1247.

30 Y.-J. Heo, J.-E. Kim, H. Weerasinghe, D. Angmo, T. Qin, K. Sears, K. Hwang, Y.-S. Jung, J. Subbiah, D. J. Jones, M. Gao, D.-Y. Kim and D. Vak, Nano Energy, 2017, 41, 443 -451 .

31 J.-E. Kim, S.-S. Kim, C. Zuo, M. Gao, D. Vak and D.-Y. Kim, Advanced Functional Materials, 2019, 29, 1809194.

32 X. Ding, J. Liu and T. A. L. Harris, AIChE Journal, 2016, 62, 2508-2524.

33 F. Jakubka, M. Heyder, F. Machui, J. Kaschta, D. Eggerath, W. Lövenich, F. C. Krebs and C. J. Brabec, Solar Energy Materials and Solar Cells, 2013, 109, 120 - 125.

34 M. Hösel, R. R. Søndergaard, M. Jørgensen and F. C. Krebs, Energy Technology, 2013, 1, 102-107.

35 C.-F. Lin, B.-K. Wang, S.-H. Lo, D. S.-H. Wong, T.-J. Liu and C. Tiu, Asia-Pacific Journal of Chemical Engineering, 2014, 9, 134-145.

36 H. Kang, J. Park and K. Shin, Robotics and Computer-Integrated Manufacturing, 2014, 30, 363 - 368. 
37 S. M. Raupp, M. Schmitt, A.-L. Walz, R. Diehm, H. Hummel, P. Scharfer and W. Schabel, Journal of Coatings Technology and Research, 2018, 15, 899-911.

38 M. Schmitt, R. Diehm, P. Scharfer and W. Schabel, Journal of Coatings Technology and Research, 2015, 12, 927-938.

39 R. Diehm, H. Weinmann, J. Kumberg, M. Schmitt, J. Fleischer, P. Scharfer and W. Schabel, Energy Technology, 0, 1900137.

40 F. C. Krebs, Solar Energy Materials and Solar Cells, 2009, 93, $465-475$.

41 S. Hong, J. Lee, H. Kang and K. Lee, Solar Energy Materials and Solar Cells, 2013, 112, 27 - 35.

42 G. Kim, J. Lee, D. Shin and J. Park, IEEE Transactions on Electron Devices, 2019, 66, 1041-1049.

43 M. S. Carvalho and H. S. Kheshgi, AIChE Journal, 2000, 46, 1907-1917.

44 M. Remeika, L. K. Ono, M. Maeda, Z. Hu and Y. Qi, Organic Electronics, 2018, 54, 72 - 79.

45 D. Burkitt, R. Swartwout, J. McGettrick, P. Greenwood, D. Beynon, R. Brenes, V. Bulović and T. Watson, RSC Adv., 2019, 9, 37415-37423.

46 D. W. de Quilettes, S. M. Vorpahl, S. D. Stranks, H. Nagaoka, G. E. Eperon, M. E. Ziffer, H. J. Snaith and D. S. Ginger, Science, 2015, 348, 683-686.

47 F. Machui, S. Langner, X. Zhu, S. Abbott and C. J. Brabec, Solar Energy Materials and Solar Cells, 2012, 100, 138 - 146.
48 L. Ye, Y. Xiong, H. Yao, A. Gadisa, H. Zhang, S. Li, M. Ghasemi, N. Balar, A. Hunt, B. T. O'Connor, J. Hou and H. Ade, Chemistry of Materials, 2016, 28, 7451-7458.

49 S. M. Mortuza and S. Banerjee, The Journal of Chemical Physics, 2012, 137, 244308.

50 J. D. McGettrick, E. Speller, Z. Li, W. C. Tsoi, J. R. Durrant and T. Watson, Organic Electronics, 2017, 49, 85 - 93.

51 J. Li, Q. Dong, N. Li and L. Wang, Advanced Energy Materials, 2017, 7, 1602922.

52 C. C. Boyd, R. Cheacharoen, K. A. Bush, R. Prasanna, T. Leijtens and M. D. McGehee, ACS Energy Letters, 2018, 3, 1772 1778.

53 Y. Kato, L. K. Ono, M. V. Lee, S. Wang, S. R. Raga and Y. Qi, Advanced Materials Interfaces, 2015, 2, 1500195.

54 C. Chen, S. Zhang, S. Wu, W. Zhang, H. Zhu, Z. Xiong, Y. Zhang and W. Chen, RSC Adv., 2017, 7, 35819-35826.

55 D.-X. Yuan, X.-D. Yuan, Q.-Y. Xu, M.-F. Xu, X.-B. Shi, Z.-K. Wang and L.-S. Liao, Phys. Chem. Chem. Phys., 2015, 17, 26653-26658.

56 S. Wang, T. Sakurai, X. Hao, W. Fu, S. Masuda and K. Akimoto, Journal of Applied Physics, 2013, 114, 183707.

57 A. Yeşildağ and D. Ekinci, Electrochimica Acta, 2010, 55, 7000 $-7009$.

58 T. J. Wilderspin, F. D. Rossi and T. M. Watson, Solar Energy, 2016, 139, $426-432$. 